\title{
Los orígenes griegos de una ciudad de Pisidia: Selge, Esparta y Calcante ${ }^{*}$
}

\author{
Héctor Arroyo Quirce \\ Universidad de Salamanca \\ hectorarroyo@usal.es
}

\section{The Greek origins of a Pisidian city: Selge, Sparta and Calchas}

\begin{abstract}
Una inscripción y una moneda imperiales atestiguan las estrechas relaciones que mantenían los selgeos de Pisidia con los lacedemonios del Peloponeso, basadas en un parentesco (syggéneia) forjado ya en época helenística como consecuencia de las conquistas de Alejandro Magno. Muchas comunidades indígenas anatolias, deseosas de ver reconocida su identidad helénica y adherirse a la cultura del poder, buscan o crean leyendas que vinculen sus orígenes con el mundo griego. En este contexto, los selgeos se emparentan con los lacedemonios, tal como refiere Polibio. Su fundamento, según las conclusiones de Curty $(1995,2001)$, debería ser un entronque mítico, pero del testimonio de Estrabón, que añade a Calcante como primer fundador, se desprende más bien un parentesco colonial. En las siguientes líneas se analiza el significado y la finalidad del parentesco espartano de Selge y de Calcante como su fundador mítico, así como su trasfondo real y ficticio.
\end{abstract}

Palabras clave: Identidad helénica, syggéneia, parentesco, leyendas fundacionales, Selge, Pisidia, Esparta, Calcante.
An inscription and a coin from imperial times prove the close relationships between the Selgians of Pisidia and the Lacedaemonians of Peloponnese. These relationships are based on a kinship (syggéneia) which was forged in hellenistic times as a consequence of Alexander the Great's conquests. Many indigenous communities of Anatolia, which are eager to see their Hellenic identity recognised and to join the culture of power, seek or create legends in order to tie their origins to the Greek world. In this context, the Selgians establish a kinship with the Lacedaemonians, as Polybius says. According to Curty's conclussions (1995, 2001), its basis should be mythical, but Strabo's words, who adds Calchas as its first founder, seem to point out a colonial link. In the next lines, it is analysed the meaning and the aim of the Selge's Spartan kinship and of Calchas as its mythical founder. In addittion to this, we look for their real and fictional background.

Key words: Hellenic identity, syggéneia, kinship, foundation legends, Selge, Pisidia, Sparta, Calchas.

* Este trabajo ha sido desarrollado en el marco del proyecto Etnicidad helénica y pervivencia indigena en un territorio de frontera cultural: la Anatolia grecorromana, FFI2011-25506. Agradezco a todas aquellas personas que han contribuido a la mejora de este artículo, especialmente a la profesora $\mathrm{M}^{\mathrm{a}} \mathrm{Paz}$ de Hoz. También quisiera agradecer las valiosas sugerencias de los informantes. 


\section{INTRODUCCIÓN: UN FENÓMENO POLÍTICO}

Originalmente grabada en la puerta de la ciudad, bajo el nicho diestro que podría haber albergado una estatua del Dêmos selgeo, una breve inscripción de principios del s. III d. C. es testigo de las buenas relaciones que mantenía la ciudad de Selge en Pisidia con el pueblo de los lacedemonios ${ }^{1}$.

ISelge 6: ed. pr. Machatschek, A. y Schwarz, M. 1981: Bauforschungen in Selge, Viena, p. 45 n. 293. Probablemente, finales de la dinastía severa. Bloque de piedra caliza partido en dos.

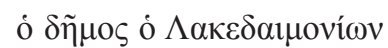

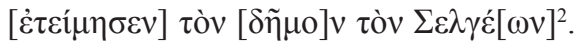

No es este el único testimonio de la conexión entre ambos pueblos: una moneda acuñada bajo el reinado del emperador Trajano Decio exhibe la celebración de la $\Sigma$ E $\Lambda \Gamma E \Omega N$ AKE $\triangle$ AIMONI $\Omega$ N OMONOIA ( $S N G F r$ 2071) ${ }^{3}$. En su relieve, la diosa Atenea, armada con su escudo y su lanza, y cuyo culto probablemente está atestiguado en Selge de antiguo, estrecha la mano de Heracles, ataviado con una clámide y sosteniendo su célebre maza, y cuya leyenda se enraíza en el Peloponeso ${ }^{4}$.

Los motivos de estas manifestaciones entre dos ciudades tan distantes y, más aún, situadas en el interior de sus respectivas regiones han de buscarse en la rivalidad que se apodera de las polis de la Anatolia grecorromana como resultado de su ambición por acumular títulos y privilegios, estimulada por una política imperial clasicista marcada por la creación de instituciones como el Panhelenion de Adriano y el surgimiento de corrientes intelectuales como la segunda sofística, con su anhelada vuelta al glorioso pasado griego ${ }^{5}$. En este contexto, el reclamo a una ascendencia griega ju-

\footnotetext{
${ }^{1}$ Para la lista de las polis de los pisidas elaborada por Artemidoro de Éfeso, en la que Selge está incluida, cf. Str. XII 7.2.

${ }^{2}$ «El pueblo de los lacedemonios [honró] al [pueblo] de los selgeos».

${ }^{3}$ Cf. Curty, Parentés 7, inscripción de los lacedemonios celebrando la concordia con el pueblo de los eleos, su pariente. Cf. Thériault 1996, p. 72 y el testimonio de D. Chr. XXXVIII

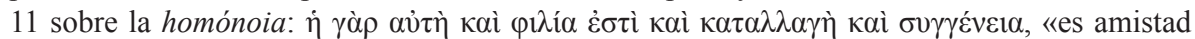
y también reconciliación y parentesco».

${ }^{4}$ Sobre esta moneda y el culto de Atenea en Selge, cf. ISelge 2.

5 Sobre este fenómeno, cf. Sartre 1994, pp. 202-210. Sobre Pisidia, cf. French 1994, p. 59, con la ascendencia jonia de los de Isinda y su posible conexión con Claros, y Takmer y
} 
gaba un papel esencial ${ }^{6}$. El elemento cultural (e. g. ágoras, gimnasios), aunque determinante, no era suficiente. Para que una comunidad pudiera ser considerada plenamente griega hacía falta contar con una ascendencia que lo confirmase. Toda la península se ve abarrotada de leyendas fundacionales y parentescos, algunos con cierta realidad histórica y otros simplemente invenciones interesadas. Se persigue sobre todo establecer vínculos con el centro étnico griego del Mediterráneo, principalmente con Argos,

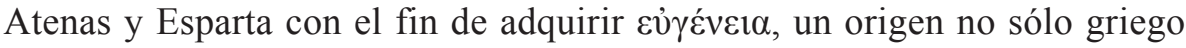
sino también noble (Robert 1977, p. 110), pero tampoco faltan las comunidades arraigadas en sus tradiciones locales, especialmente si aportan antigüedad y pueden ser relacionadas con sucesos tales como la guerra de Troya $^{7}$. Las posibilidades son variadas y flexibles ${ }^{8}$. Así, en Pisidia, los termeseos pueden reclamar que los hijos de Agamenón habían fundado el segundo culto más importante de su patria, el de Ártemis Tauropólos (Nollé 2009), sin dejar de incidir en su identidad sólima, una tribu minorasiática mencionada por Homero en relación con el héroe Belerofonte (Il. VI 184) ${ }^{9}$.

El papel económico y estratégico que juega Selge en la política internacional de los emperadores romanos del siglo III d. C. frente a las campañas en Oriente es sin duda lo que explica la insistencia en los vínculos con Esparta y el embellecimiento urbanístico que experimenta la ciudad, impulsados por el patriótico interés de familias y notables locales como Septimio Mano, que llega a ocupar el puesto de gobernador de LiciaPanfilia, y los Plancios Magnianos, dominadores absolutos de las principales magistraturas, en situar a su comunidad en lo más alto de la jerarquía cívica ${ }^{10}$. Los lazos de Selge con Esparta, sin embargo, no eran algo

Gökalp 2005, con la posible admisión de la ciudad de Timbriada en el Panhelenion. Sobre la influencia de esta institución, cf. Jones 1996.

${ }^{6}$ La descendencia común putativa es un criterio fundamental en la definición del grupo étnico y siempre estuvo presente en la configuración de una identidad helénica. Cf. en general Hall 1997 y 2002, Malkin 2001, Saïd 2001, Romeo 2002, Ruby 2006, Luraghi 2008 y Derks y Roymans 2009; contrariamente a la definición de romanitas, cf. Woolf 1994.

7 Para todas las posibilidades, cf. Strubbe 1984 y Weiss 1984. Sobre la noción de nobleza y antigüedad, cf. Heller 2006.

${ }^{8}$ Cf. por ejemplo Heller 2009.

9 Sobre los sólimos, cf. Gonzales 2005, de Hoz 2006 y Coulton 2008. Para el héroe Sólimo en Termeso, cf. Kosmetatou 1997a.

${ }^{10}$ Para una historia de la ciudad, cf. Nollé y Schindler 1991, pp. 13-16. Cf. ISelge 12 en honor de Septimio Mano: reclamo de primacía y título de amiga y aliada de los romanos 
nuevo, sino que habían sido forjados mucho antes. La comunidad simplemente estaba renovando en época imperial un parentesco existente desde, por lo menos, el siglo II a. C., siendo las Historiae de Polibio la primera fuente (V 76. 11). Las conquistas de Alejandro Magno y el posterior gobierno de sus sucesores en Pisidia habían hecho conscientes a las poblaciones autóctonas más familiarizadas con la civilización griega de las ventajas de adherirse a la ideología del nuevo poder político mediante una identidad helénica basada en relatos de fundación ${ }^{11}$. Para los selgeos, los lacedemonios iban a ser la apuesta principal en su identidad para tender un puente con el helenismo, un puente apuntalado posteriormente por la figura del adivino Calcante, venido según la tradición desde la lejana Troya.

\section{Selge y Esparta: un Parentesco en ÉPoca helenística}

\section{Syggéneia: parentesco mítico}

El comentario de Polibio sobre el parentesco que une a ambas comunidades se inserta en el relato de la guerra que mantienen los selgeos contra Aqueo, usurpador del trono de Antíoco III, con motivo del asedio de la ciudad de Pedneliso (Plb. V 72-77). Tras toda una serie de estratagemas y toma de posiciones, los selgeos son terriblemente derrotados por el ejército helenístico y se refugian en su ciudad. Viendo perdida toda esperanza de salvación, encargan a su ilustre conciudadano Lógbasis, amigo de Antíoco Hierax y tutor de la futura esposa de Aqueo, Laódice, que negocie la rendición, pero este decide traicionar a su patria. Con toda la ciudad desprotegida y distraída en debates sobre la conveniencia de aceptar las falsas promesas de paz ofrecidas, Lógbasis, que había ido recibiendo en su casa a los soldados de Aqueo que habrían de ayudarle en su traición, da la señal al ejército que esperaba fuera de iniciar el ataque. La estrategia habría tenido éxito de no ser porque

(s. III d. C.). Cf. SEG 2.735 para Sagalaso: sagrada, ilustre y gloriosa neocora por segunda vez, primera de Pisidia, amiga y aliada de los romanos (fin s. III d. C.). Esta ciudad también celebra con una moneda la concordia con Esparta, cf. Franke y Nollé 1997, n. ${ }^{\circ} 1794$ (Filipo II). Como héroe fundador reclamaba a Lacedemón, cf. BMC 13: $\Lambda$ AKE $\triangle \mathrm{AIM} \Omega \mathrm{N}$ САГА ААССОС (161-180 d. C.).

${ }^{11}$ Cf. Kosmetatou 1997b para la historia helenística de la región. Para el proceso de helenización de Pisidia, cf. los trabajos de Mitchell 1991, Waelkens 2004 y Vanhaverbeke y Waelkens 2005. 
un cabrero, viendo al enemigo en marcha hacia el templo Kesbelion, dio la voz de alarma: de los selgeos, unos rápidamente ocuparon la ciudadela sobre la que se levantaba el templo y otros se dirigieron a casa de Lógbasis para lincharlo, a él y también a sus hijos y cómplices. Consiguieron defender su ciudad, pero conscientes de su inferioridad trataron la rendición con Aqueo, que les impuso como condiciones la devolución de los rehenes pedneliseos y el pago de setecientos talentos. He aquí que Polibio concluye:

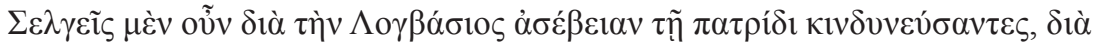

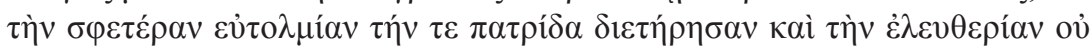

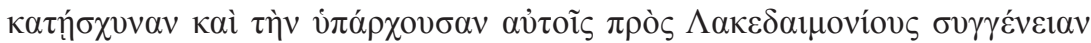
$(\mathrm{V} 76.11)^{12}$.

El término griego acostumbrado para describir los lazos de parentesco es syggenés/syggéneia — de tal suerte que la referencia de Polibio es palmaria,

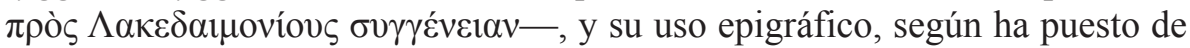
relieve O. Curty, autor de un corpus con todas las inscripciones griegas en las que aparece el vocablo, está acotado por unas condiciones muy precisas $(1995, \text { p. } 216)^{13}$ :

Le titre de parent obéit donc à des règles contraignantes. Pour y avoir droit, il faut impérativement posséder une parenté héroïque ou divine avec la cité qui concède le titre, c'est-à-dire, le plus souvent, que les fondateurs de chaque cité soient parents.

Del parentesco de los selgeos con los lacedemonios, cuya noticia llega a través de la literatura, sin embargo, no hay ningún testimonio epigráfico,

12 «Así pues, los selgeos, que habían puesto en peligro su patria por la impiedad de Lógbasis, la retuvieron gracias a su coraje, y no deshonraron ni su libertad ni su parentesco con los lacedemonios».

${ }^{13}$ La cuestión del parentesco ha sido tema de controversia desde la aparición de su tesis en 1995, Les parentés légendaires entre cités grecques, aunque ya fue tratada anteriormente en numerosas ocasiones de forma sucinta por L. Robert (cf. por ejemplo 1977), y en concreto por

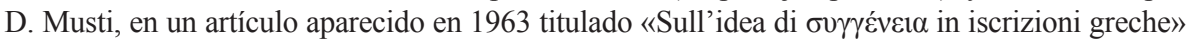
(ASNP 32, pp. 225-239), y S. F. Elwyn (1991). Más recientemente, S. Lücke (2000) ha dedicado toda una monografía a esta cuestión, optando por un sentido figurado de syggéneia. Para este estudio se siguen las conclusiones de Curty (1995), que reafirma su posición y metodología ante sus críticos (1999, contra Hall, Giovannini, Will) y se ocupa de refutar la tesis de Lücke (2005). Sobre usos diplomáticos del parentesco, cf. los trabajos de Jones 1999 y Patterson 2010. 
y por lo tanto no es analizada en la tesis de Curty $(1995)^{14}$. Este hecho, no obstante, no supone en principio un impedimento para su estudio, pues en otro artículo el propio Curty (2001) afirma que los textos literarios -Estrabón, Plutarco, Pausanias y Polibio- arrojan las mismas conclusiones que extrajo en su análisis de los textos epigráficos ${ }^{15}$. Así pues, el testimonio de Polibio remitiría precisamente a este mismo procedimiento y, siempre según Curty $(1995,2001)$, el uso del término syggéneia hace que el fundamento de la relación entre Selge y Esparta deba buscarse en la mitología de ambas ciudades, esto es, un dios/héroe relacionado con Selge debe estar emparentado en algún grado con un dios/héroe de Esparta. Sirva como ejemplo el parentesco de Termeso en Pisidia con Milasa, atestiguado en una inscripción incluida en una serie de dedicaciones a Zeus Osogo, uno de los cultos más importantes en la ciudad caria (93/94 d. C.) (Parentés 69): Curty propone las figuras de Belerofonte y Milaso como justificación, ambos descendientes de Glauco. No hará falta señalar que la pertenencia a un misma subetnia griega — doria, jonia o eolia—, requisito que había ido perdiendo peso en el establecimiento de parentescos a medida que se expandía la civilización griega, no sería necesaria en el caso de Selge, dado que estamos ante una ciudad pisida ${ }^{16}$. Por desgracia, Polibio se limita a señalar que existe una syggéneia, no en razón de qué dioses o héroes se ha establecido. El culto local de Heracles en Selge, en origen un dios indígena revestido con un nombre griego, pudo haber sido aprovechado, aunque es difícil ver cómo. Era un emblema para la identidad religiosa de la comunidad: compartía con Zeus el espacio sagrado del principal templo de la ciudad, el Kesbelion, y aparecía frecuentemente en las monedas locales de época helenística (Nollé 2000, p. 709) ${ }^{17}$.

${ }^{14}$ La menciona en una nota al pie (1995, p. 206 n. 210).

15 «Elle (la parenté) se justifie par les mêmes critères dans les textes littéraires que dans les inscriptions, c'est-à-dire que si deux héros ayant des rapports privilégies avec un cité, possèdent entre eux des liens de parenté, ces liens rejaillissent sur les cités auxquelles ils sont attachés» (2001, p. 54).

${ }^{16}$ Cf. Curty 1999, pp. 181-184.

${ }^{17}$ En Amblada, una comunidad pisida que en época imperial también reclama una ascendencia lacedemonia (cf. $A S 18,1968$, p. 76 n. ${ }^{\circ} 21$, p. 77 n. ${ }^{\circ} 23$ ), Heracles, además de ser representado en las acuñaciones del s. I a. C., da nombre a una phylé, cf. $A S 18,1968$, p. 79 n. ${ }^{\circ} 26$. En varias series entre los siglos II-III d. C. se acuña el título AMB $\Lambda$ A $\triangle \mathrm{C} \Omega \mathrm{N} \Lambda \mathrm{AKC} \triangle \mathrm{AIMONI} \Omega \mathrm{N}$, cf. Aulock 1977, n. ${ }^{\circ}$ 123, 125-170. Para el culto de Heracles en Pisidia, cf. Talloen 2015, pp. 94-95. 


\section{Parentesco colonial: el testimonio de Estrabón sobre Selge y los lacedemonios}

Será Estrabón el que un siglo más tarde aluda de nuevo a los lazos existentes entre selgeos y lacedemonios. Su testimonio, sin embargo, oscurece el parentesco de Selge, cuyo significado mítico parecía en un principio evidente:

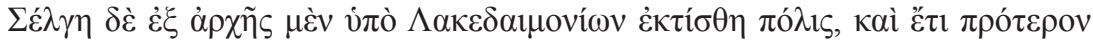

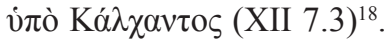

Las palabras del geógrafo, cuya fuente es presumiblemente Posidonio de Apamea (ca. 135-51 a. C.) ${ }^{19}$, insertan la relación de Selge con Esparta en el ámbito de la colonización. La ausencia de una personalidad mítica que desempeñe la función de segundo oikistés al mando de los lacedemonios así como la cronología posterior a la guerra de Troya que lleva implícita el relato aludido en el texto hablan en favor del carácter posheroico de la fundación ${ }^{20}$. En definitiva, deberíamos optar aquí por un vínculo colonial situado en época histórica entre Selge y Esparta, mientras que una interpretación tal en las syggéneiai de Polibio conllevaría ciertas contradicciones metodológicas: como señala Curty 2001, p. 51, de las Historiae se desprende que el historiador sí distingue

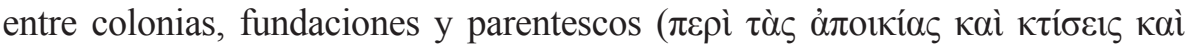

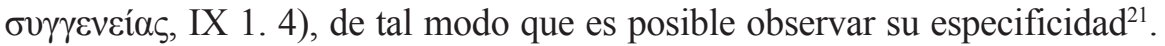

\section{El parentesco de Selge: ¿mítico y/o colonial?}

La opción más sencilla para reconciliar ambas posturas sería reducir toda la cuestión a un aspecto de transmisión, es decir, suponer que los dos autores transmiten bien el doble vínculo por separado, bien un momento distinto en la helenización de la ciudad. Selge podría haber contado inicialmente como comunidad no griega con un parentesco mítico con Esparta, que habría evolucionado a, o sido sustentado mediante, un parentesco colonial conforme la ciudad se iba integrando en el mundo griego y aumentaba el prestigio de su supuesta

18 «Selge, en cambio, fue fundada desde el principio como ciudad por los lacedemonios, $\mathrm{y}$ aún antes por Calcante».

19 Lasserre 1981, pp. 21-26.

${ }^{20}$ Cf. las opiniones de Scheer 1993, p. 212, y Paluchowski 2008, p. 52.

${ }^{21}$ Los otros pasajes metodológicos de Historiae seleccionados por Curty (2001) son XII 26d.2; IX 2.1-2; XXXIV 1.3-4. 
metrópolis en el Mediterráneo (infra) ${ }^{22}$. El principal inconveniente para esta hipótesis es que los comentarios de Estrabón sobre las buenas instituciones de Selge parecen rendir tributo a los de Polibio sobre el coraje de sus ciudadanos, en la medida en que ambos ponen de relieve virtudes espartanas. El círculo está muy cerca de cerrarse cuando se descubre que las Historias de Posidonio de Apamea, la posible fuente de Estrabón para Selge, continuaban las de Polibio ${ }^{23}$.

Otro argumento difícil de obviar es que tanto la fundación de Aspendo en Panfilia por Argos, que probablemente sirvió de modelo para Selge (infra), como los autores tardíos privilegian la colonización como el nexo con Esparta ${ }^{24}$. Teniendo en cuenta estos hechos, existe la posibilidad de que en la syggéneia de Polibio para Selge hubiera interferido el dominio de la colonización, dado que una colonia es por naturaleza pariente de su metrópolis (Curty 1995, p. 221 $)^{25}$. Un pasaje de Historiae, de hecho, refleja la interacción entre ambas esferas, pero el caso es que se usa un vocabulario muy específico. El argumento de los rodios para hablar en favor de los habitantes de Solos en Cilicia frente al senado de Roma es que los une una syggéneia que Polibio relaciona

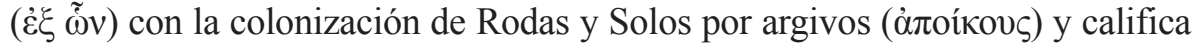

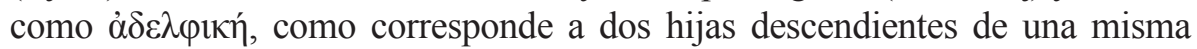
metrópolis (Curty 1995, p. 218) ${ }^{26}$. El estudio de otros parentescos lacedemonios en las Historiae parece confirmar a primera vista la ligazón con el ámbito colonial, ya que allí se describen las relaciones entre Tarento y Esparta, por un

${ }^{22}$ Cf. Curty 1995, pp. 259-260; 1999, pp. 169-173, para el caso de la ciudad caria de Alabanda y el parentesco entre Heraclea del Latmo y los etolios.

${ }^{23}$ Cf. de Hoz 2003, p. 16.

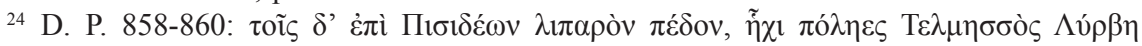

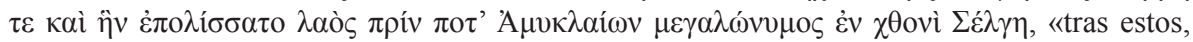
la fértil tierra de los pisidas, donde están las ciudades de Telmeso, Libre y la que fundó en

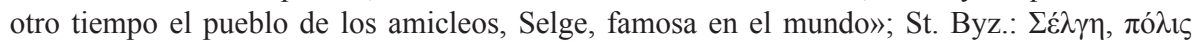

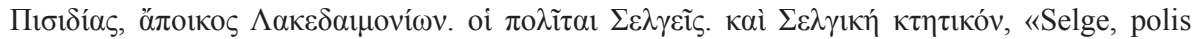
de Pisidia, colonia de los lacedemonios. Los ciudadanos, 'selgeos'. Y 'sélgica', el posesivo.

${ }_{25}$ No obstante, las ciudades sí suelen distinguir entre colonias y ciudades parientes en sus inscripciones, cf. Curty 1995, pp. 220-221, con el ejemplo de Mileto. Cibira también distingue: declara ser «colonia de los lacedemonios y pariente de los atenienses» (Curty, Parentés 81:

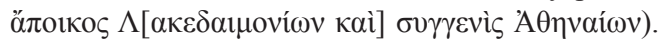

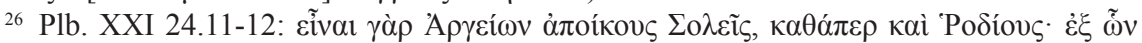

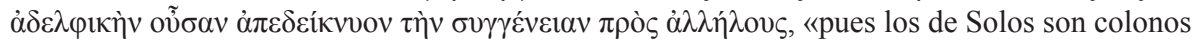
de los argivos, al igual que los rodios, con lo que demostraban que había un parentesco de hermanos entre ellos». 
lado, y Esparta y Lito, por otro, mediante la expresión ápoikos kaì syggenés - uno podría deducir que son parientes de Esparta porque son sus colonias ${ }^{27}$. No obstante, los pasajes metodológicos de Polibio citados arriba hacen que la interpretación más lógica sea que ambos se sustentan en un doble lazo, uno colonial y otro mítico. En resumen, habría que entender cada término por separado y en su sentido completo. Si no hubiera una distinción en la mente del historiador, resultaría superfluo precisar ápoikos mediante syggenés, mientras que lo contrario no siempre es cierto: un pariente mítico no tiene por qué ser colonia $^{28}$. Poco importa aquí cuál haya sido la naturaleza o la historicidad de estas fundaciones ${ }^{29}$. En vista de los inconvenientes, una solución intermedia es entender, de acuerdo con el contexto del pasaje, que mediante la expresión $\pi \rho \grave{\varsigma} \varsigma$

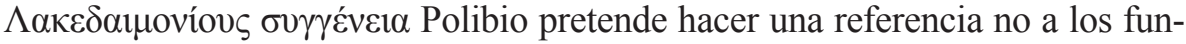
damentos míticos de la relación entre ambas comunidades, sino a los vínculos de sangre que determinan el carácter específico guerrero de los selgeos como resultado de un supuesto proceso de colonización por lacedemonios, transmitido como tal en la Geografía de Estrabón ${ }^{30}$. A pesar de sus esfuerzos, las conclusiones de Curty sobre la syggéneia en Polibio (2001) no son tan claras como él pretendía en un principio.

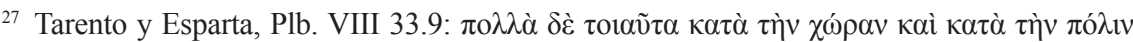

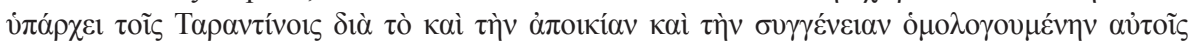

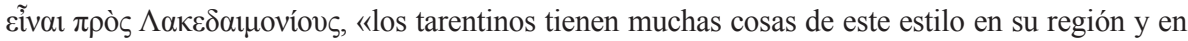
su ciudad debido a que son una colonia de los lacedemonios y a que tienen con ellos un paren-

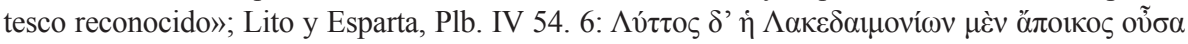

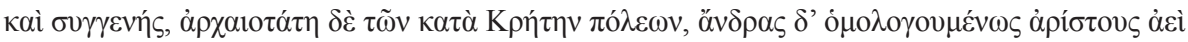

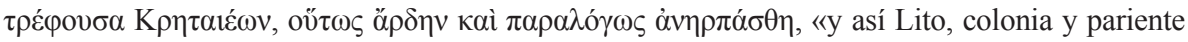
de los lacedemonios, la más antigua de las ciudades de Creta, y que siempre ha criado a los hombres reconocidos como los mejores de los cretenses, fue total e inesperadamente borrada del mapa». Curty (2001) obvia este último parentesco. Hay otros dos en Polibio, pero se refieren a pueblos bárbaros (II 19. 1: galos cisalpinos y transalpinos; XXXIV 9.3: turdetanos y túrdulos).

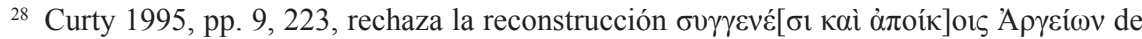
Stroud (1984, p. 200) en el decreto entre Argos y Aspendo (s. IV a. C.) —haciéndose eco de la noticia de Estrabón según la cual la ciudad panfilia es una fundación de argivos (XIV 4.2) - y

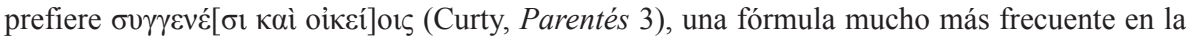
epigrafía para describir los lazos entre metrópolis y colonias.

${ }^{29}$ Sobre Tarento, cf. Nafissi 1995, pp. 263-302. Sobre el fundador Falanto, cf. Corsano 1979. Sobre Lito como colonia espartana, cf. Malkin 1994, pp. 79-80.

${ }^{30}$ Elwyn 1991, pp. 44-49, discute brevemente el significado de syggéneia en Polibio, y sobre Selge concluye que se trata de un lazo resultante de la colonización, de igual modo que el de Tarento y Solos. 


\section{III. ¿Aqueos y dorios en Selge? El influjo de Panfilia}

Toca ahora preguntarse de dónde, cuándo, cómo y por qué surgen los orígenes griegos de Selge. Se impone en los últimos tiempos una tendencia que opta por considerar los relatos de fundación como invenciones y manipulaciones de las élites locales, surgidos en un momento concreto para responder a necesidades concretas y proyectar al mundo la imagen que desean de ellas mismas y, por extensión, de su comunidad ${ }^{31}$, pero sería perjudicial detenerse ahí, toda vez que los substratos lingüísticos aqueo y dorio del dialecto panfilio, analizado por Brixhe (1976), proporcionan un trasfondo étnico histórico adecuado en el que insertar las leyendas de fundación de Selge $^{32}$. En pocas palabras, no se debe realizar una interpretación positivista según la cual Selge es una fundación aquea y una colonia espartana históricas ${ }^{33}$, pero la presencia de elementos griegos en la llanura panfiliana obliga a cuestionarse cómo pudo afectar en la elaboración del mito. Las ciudades de Panfilia, situadas inmediatamente al sur de la región montañosa de Pisidia, son el punto de partida para la siguiente investigación. Especialmente determinante en la elección de Calcante y de Lacedemonia por Selge parece haber sido la polis de Aspendo, con su doble fundación por Leonteo y Polipetes primero y por Argos después. Su cercanía geográfica y sus conexiones comerciales, facilitadas por el río Eurimedonte, la hacen el modelo más plausible: ambas comunidades acuñan moneda de forma conjunta a finales del s. V a. C. ${ }^{34}$

Las fundaciones por Calcante, Leonteo y Polipetes remiten a la misma tradición mítica: las expediciones que tras la caída de Troya encabezaron los héroes adivinos hacia el sur de Asia Menor. Otras ciudades próximas como

${ }^{31}$ Cf. Mac Sweeney 2015, pp. 3-7 sobre las diferentes aproximaciones a los mitos de fundación.

${ }^{32}$ Sobre la influencia eolia, quizás más importante de lo que se estimaba inicialmente, cf. Brixhe y Tekoğlu 2000, pp. 52-53. Los de Side decían ser una fundación de Cime (Arr., An. I 24. 4).

${ }^{33}$ La propuesta de Woodward (1953) que sustentaba el culto de Helena y los Dioscuros en una presencia histórica espartana en las primeras colonias seléucidas fue totalmente rechazada por Robert 1983, p. 565. Cf. también Curty 1995, p. 261 y Musti 1963, p. 239. Malkin 1994, p. 64, la cataloga como «patently fictive Spartan kinship». Lücke 2000, pp. 106-107, también traza la cuestión de un posible núcleo histórico en la ingente cantidad de colonias espartanas en Asia Menor.

${ }^{34}$ Cf. Brixhe 1976, pp. 196, 288-290. 
Fasélide, Silion y Perge, también la utilizaban de un modo más o menos directo. Ilustrativa es la puerta principal de esta última en época imperial, en donde se presenta como fundadores míticos de la ciudad a Calcante, Leonteo y Mopso, entre otros (IPerge 101, 103, 106). Unida al substrato aqueo del dialecto panfilio, esta tradición podría ser la narración mítica de un hecho histórico, i. e. la llegada a Panfilia de pobladores micénicos en la segunda mitad del II milenio a. C., antes o durante las invasiones dorias ${ }^{35}$, pero es más bien dudoso que Selge se hubiera visto afectada. Que los recién llegados aqueos tuvieran contactos con las poblaciones indígenas en la llanura entra dentro de lo imaginable ${ }^{36}$, pero ni Selge está atestiguada para esta época, ya sea arqueológica o epigráficamente ${ }^{37}$, ni las acuñaciones monetarias prueban nada a este respecto. Si bien es cierto que en ellas se expresa el étnico epicórico en panfilio hasta el 300 a. C. ( $\Sigma$ T $\Lambda$ ELIIY $\Sigma$, E $\Sigma$ T $\left.\Lambda E \Gamma I I Y \Sigma^{38}\right)$, la serie más antigua data de finales del siglo $\mathrm{V}$ a. C. Los selgeos de época clásica simplemente habrían adoptado una lengua ya configurada con el substrato aqueo y habrían aprovechado el poso mítico que situaba la expedición de Calcante cerca de sus límites territoriales. Estrabón sitúa su muerte en Colofón tras un enfrentamiento con Mopso (XIV 1.27), lo que evidentemente habría imposibilitado su presencia en el sur de Asia Menor, pero pocas líneas después (XIV 1.27, 5.16) el propio geógrafo menciona otros autores que trasladan el episodio de la muerte del supuesto fundador de Selge a Cilicia, como Sófocles en su Reclamación de Helena, llamada de acuerdo con la costumbre de la tragedia Panfilia, en lo que supone un magnífico ejemplo de

${ }^{35}$ Cf. Brixhe 1976, pp. 147, 287. Scheer 1993, pp. 213-214, parece restar importancia a la evidencia lingüística aquea; cf. Dowden 1999, p. 29.

${ }^{36}$ Más difícil es valorar el impacto de estos contactos. Cf. Waelkens 2000, p. 473, sobre una necrópolis hallada en las cercanías de la actual Düger, próxima a la antigua Sagalaso y el único yacimiento de la región fechado en la edad del Bronce (temprano), con trazos de influencia micénica. En referencia a la llegada de micénicos a la llanura panfiliana, Brixhe 1976, p. 148, opina que «le grec dut s'imposer rapidement aux autochtones. ... Mais il (le grec) était constamment alimenté par l'arrivée de nouveaux 'inmigrants' venant de la campagne et de l'arrière pays».

${ }^{37}$ Hay que ser conscientes, no obstante, de los riesgos de este argumento, ya que futuras excavaciones pueden cambiar el panorama. En los territorios de las clásicas Pisidia y Panfilia ya hay asentamientos durante el Bronce tardío, fuera cual fuera su naturaleza: bajo los topónimos Sallawassa, Kuwalapassa, Wattana y Parha, mencionados por fuentes hititas (s. XIII a. C.), probablemente estén Sagalaso, Colbasa, Etena y Perge. Cf. en conjunto Waelkens 2000. Para Etena, cf. Nollé 1992, p. 74 n. 108.

${ }^{38}$ Cf. Brixhe 1976, p. 288, con más variantes. 
las diferentes versiones que circulaban en el mundo antiguo y que podían ser aprovechadas por las ciudades para colmar sus ambiciones políticas ${ }^{39}$.

La interacción con una migración doria, por su parte, proporciona un

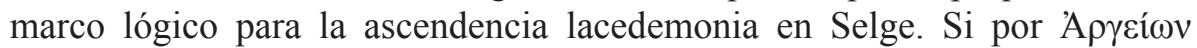
$\kappa \tau i ́ \sigma \mu \alpha$ (Str. XIV 4.2) se entiende que Aspendo es una fundación histórica a cargo de la ciudad de Argos, la conexión es bastante transparente: los colonos habrían traído consigo su propia historia mítica, con sus dioses, héroes y hazañas, y los contactos entre Selge y Aspendo, entre la montaña y la llanura, habrían propiciado un continuo fluir cultural que habría desembocado en desarrollos paralelos en ambas comunidades. Una fundación histórica de Aspendo por Argos, sin embargo, ha sido rechazada por Scheer 1993, pp. 216-222. Justifica su decisión en la aparente poca participación de Argos durante los procesos de colonización, a pesar de ser una de las ciudades más preeminentes de la Grecia continental. La posesión de suficientes terrenos de cultivo y su localización interior y privada de acceso inmediato al mar, en contra del emplazamiento habitual de las grandes polis colonizadoras como Corinto, parecen argumentos sólidos a favor de su interpretación. El substrato lingüístico dorio que Brixhe rastrea en el dialecto panfilio ella lo atribuye a la acción colonizadora mucho más factible de los rodios, con la fundación de ciudades como Fasélide y Rodiápolis ${ }^{40}$. Rodas explicaría también la existencia de hechos culturales comunes con algunas comunidades de Panfilia, tales como el culto de Zeus Machaneos en Perge, el motivo del hondero en las monedas o, aún más revelador, el modelo fundacional mismo de Aspendo, pues los rodios se vinculaban tanto con la guerra de Troya como con los argivos. La elección de Argos como madre fundadora por Aspendo, además de proporcionar el prestigio de la épica griega, habría sido decidida con el fin de evitar posibles reclamos territoriales rodios en la zona.

En un contexto tal, a nadie le extrañaría que las élites de Selge adoptasen para su propia comunidad algunas de las costumbres percibidas entre sus vecinos, entre ellas, la posesión de leyendas fundacionales de orígenes griegos. La estrategia identitaria de sus homólogos en Aspendo no sólo les había proporcionado prestigio y antigüedad, sino que también les reportaba ventajas materiales, como demuestra el decreto en el que se menciona su parentes-

${ }^{39}$ Cf. Scheer 1993, pp. 182-216, para la interpretación colectiva de los mitos de fundación en Panfilia con motivo de la expedición de los adivinos.

${ }^{40}$ Arriano (An. I 24.6) cuenta que los faselitas eran a menudo atacados por pisidas. 
co con Argos: la concesión de ciudadanía, el acceso a la asamblea y el derecho a participar en los concursos y procesiones son algunas de ellas ${ }^{41}$. La prosperidad que ofrecía un origen griego en un mundo cada vez más interconectado era un incentivo difícil de rechazar. Los selgeos, sin embargo, no iban a limitarse a elaborar una simple copia de las fundaciones de Aspendo. Tenían sus propias aspiraciones de acuerdo con sus características y el curso de los acontecimientos históricos en Pisidia y en el Mediterráneo. Esparta y Calcante iban a ser sus herramientas para intentar alcanzarlas.

\section{Las ambiciones de Selge: Esparta y Calcante}

La evolución que construye la ciudad de Cibira desde unos orígenes lidios y pisidas en el cambio de era (Str. XIII 4.17) hacia una doble ascendencia lacedemonia y ateniense en época imperial con el objetivo de ingresar en el Panhelenion de Adriano (Curty, Parentés 81) refleja de forma inmejorable la manipulación de los mitos de origen y su adaptación a las necesidades del presente a cargo de las élites locales, sin duda las más interesadas en incorporarse a las nuevas estructuras implantadas por los gobernantes grecorromanos, pero también las más capacitadas tanto política como culturalmente ${ }^{42}$. Flavia Platonis, miembro de la nobleza de Cibira en época imperial, traza su genealogía precisamente hasta los fundadores espartanos Amiclas y Cleandro ${ }^{43}$. El episodio de Lógbasis en Selge, en el que se descubre su amistad con Antíoco Hierax, su papel de tutor de Laódice y su colaboración con Aqueo en contra de su propia patria, por su parte, pone de relieve los vínculos de las capas superiores de la sociedad local con el poder central así como la influencia que ejercían sobre sus conciudadanos. En qué momento decidió la clase dirigente de Selge crear unos orígenes griegos para su ciudad y por qué eligió Esparta y Calcante, sin embargo, son cuestiones un tanto complicadas, aunque al menos es indudable que el parentesco con Esparta es anterior a la muerte de Polibio. El historiador, llevado a Roma en el 167 a. C., pudo incluso haber

${ }^{41}$ Cf. Stroud 1984. Cf. también Lücke 2000, pp. 90-91.

${ }^{42}$ Cf. Curty, Parentés 5 (s. II d. C.), sobre el papel del rétor Publio Antio Antíoco, ciudadano de Egas en Cilicia, en la elaboración de relatos locales para demostrar una syggéneia con Argos, basada en la figura de Perseo. En la línea 19 se menciona de forma expresa su perfecta paideía.

${ }^{43}$ Cf. Hall, Milner y Coulton 1996. Sobre el uso de genealogías heroicas por individuos o familias, cf. Jones 2010. 
entrado en contacto directo con los embajadores selgeos que, a instancias del rey Prusias II de Bitinia, habían acudido al senado para quejarse de Eumenes II de Pérgamo (Plb. XXXI 1.3) ${ }^{44}$ y haber conocido la información de primera mano. Ese era un buen lugar y un buen momento para que los representantes de Selge expusieran sus vínculos con el prestigioso pueblo del Peloponeso, en su insistencia por salvaguardar su autonomía e independencia frente a las ambiciones de la dinastía atálida en la región ${ }^{45}$.

La embajada que envía Selge a Alejandro Magno para solicitar su amistad tan pronto este pone los pies en Pisidia (Arr., An. I 28.1), aunque un momento propicio para reclamar un origen griego ${ }^{46}$, no parece el más adecuado para uno lacedemonio, dado que las relaciones entre el rey y Esparta eran algo tensas en aquellos años ${ }^{47}$. La descripción de los selgeos en las fuentes de Arriano, contemporáneas a Alejandro Magno ${ }^{48}$, como

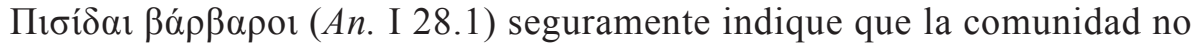
había sentido la necesidad de arrogarse un pasado griego antes de la llegada de la superpotencia macedonia y de su inclusión de lleno en el helenismo. Una posibilidad más segura y ventajosa para explicar la elección de Selge es la que sugieren Spawforth y Walker 1986, p. 96, según la cual el prestigio de una ascendencia espartana en oriente pudo haber sido realzado por la amistad de Esparta con los Ptolomeos durante su período de talasocracia en el siglo III a. C. Es significativo a este respecto que la dinastía ptolemaica, que gobernó durante algún tiempo Panfilia y algunas ciudades pisidas cercanas como Termeso $^{49}$, se representaba a sí misma como descendiente del héroe Heracles (Theoc. XVII 26-27), una divinidad especialmente venerada en Selge, como ya se ha apuntado. La afinidad cultural que les proporcionaban semejanzas cultuales como la de Heracles y su carácter guerrero era un magnífico argumento de

${ }^{44}$ Cf. Walbank 1957, pp. 33-34, sobre las diferentes fuentes que pudo utilizar Polibio.

${ }_{45}$ Sobre las malas relaciones entre Selge y los Atálidas, cf. Kosmetatou 1997b, pp. $24-$ 28. Un decreto de Olbasa en la Milíade en honor de dos oficiales reales menciona Пıбıðкòs

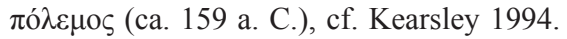

${ }^{46}$ Cf. Arr., An. I 5.9, en donde se afirma que Alejandro perdonó el tributo que los habitantes de Malo en Cilicia pagaban a Darío porque eran colonos de los argivos y él mismo se consideraba descendiente de los Heraclidas de Argos.

${ }^{47}$ Cf. Faraguna 2003, pp. 99-115.

48 Principalmente, Ptolomeo y Aristóbulo, cf. Bosworth 1980, pp. 16-34.

${ }^{49}$ Cf. Kosmetatou 1997b, pp. 18-20. 
identidad étnica común con los lacedemonios ${ }^{50}$. Otras supuestas fundaciones suyas en Pisidia, como Sagalaso y Amblada, sin duda se sirvieron de un razonamiento semejante para sus reclamos ${ }^{51}$. La cercanía de Lógbasis y Antíoco Hierax ofrece otro marco adecuado, pero se nos escapan los detalles del porqué se habría favorecido una ascendencia espartana por aquel entonces. Quizás la élite de Selge buscase distinguirse de la argiva Aspendo. Aunque las relaciones entre ambas parecen haber sido buenas en un principio, factores de tipo territorial y hegemónico pudieron influir en el desarrollo de una oposición fundacional, sobre todo cuando Selge se mostraba cada vez más como una potencia en expansión digna de ser temida ${ }^{52}$. Aspendo es una de las ciudades que envían hoplitas en apoyo del ejército de Aqueo para impedir la toma de Pedneliso por los selgeos (Plb. V 73.3).

La competitividad con las ciudades de la llanura de Panfilia es la mejor manera de explicar la primera y única mención sobre la fundación de Selge a cargo de Calcante. Su elección posiblemente se viera favorecida por un factor cultural regional: la costumbre de la adivinación, de fuerte arraigo en Pisidia $^{53}$. Puede que en la vecina polis de Adada también hubiese operado este criterio: se ha sugerido que al menos uno de los dos fundadores de un oráculo alfabético podría hacer remontar los orígenes de su familia al mismo adivino (Nollé 2007, p. 235). Su figura como fundador, sin embargo, no parece haber calado en la ideología de la ciudad de Selge. Ni su busto está grabado en las monedas de la ciudad, en contra de la costumbre atestiguada en otras polis minorasiáticas, que sitúan a sus héroes mitológicos como el más noble motivo de orgullo ${ }^{54}$, ni tampoco se le reserva un hueco en la puerta principal, en donde estaba la inscripción que daba comienzo a

${ }^{50}$ Cf. Scheer 1993, p. 217; Lücke 2000, p. 107; Nollé y Schindler 1991, p. 13 n. 11, sobre el escudo como objeto de veneración en Selge.

${ }^{51}$ Cf. nn. 10 y 18. Los Dioscuros, fuertemente vinculados con Esparta, son otro ejemplo de deidades indígenas adaptadas a las nuevas circunstancias de la cultura griega en Pisidia. Son representados en las monedas de varias ciudades, entre ellas Sagalaso, cf. Talloen 2015, p. 99. Los habitantes de esta última son definidos en la Anábasis de Arriano (I 28.2) como

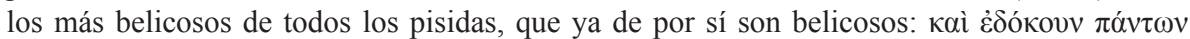

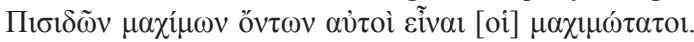

${ }^{52}$ Scheer 1993, p. 217, rechaza esta posibilidad.

${ }_{53}$ Cf. Nollé 2000, pp. 708-709; Talloen 2015, pp. 146-147.

${ }^{54}$ Cf. Robert 1977, muy ilustrativo de la función del héroe en la numismática local. 
estas líneas (ISelge 6) ${ }^{55}$. Durante la época de la pax romana muchas ciudades adornaron sus puertas principales con las estatuas de sus fundadores míticos, como la célebre puerta de Perge, pues era el lugar ideal para exaltar los orígenes de la ciudad y su reputación ante los ojos de todos (Nollé y Schindler 1991, p. 77). A estas lagunas se añade también la inexistencia del habitual culto al fundador (Scheer 1993, p. 215). Con todo, no es difícil valorar su repercusión: Calcante proveía a Selge de un pasado antiquísimo y de un vínculo directo con el súmmum de la helenidad, tanto geográfica - el corazón de Grecia - como cronológicamente - la expedición panhelénica bajo el cetro de Agamenón para derribar los muros de Troya y devolver a Helena a su legítimo esposo.

\section{SÍNTESIS FINAL: LA CONSTRUCCIÓN DE UNA GENEALOGÍA ILUSTRE}

En algún momento de su historia helenística, los selgeos decidieron relegar a un segundo plano sus antiguas raíces luvitas ${ }^{56}$ y sembrar una nueva identidad helénica, basada principalmente en un parentesco con el pueblo de los lacedemonios y adornada oportunamente mediante el adivino Calcante. $\mathrm{Su}$ presto pacto de alianza con Alejandro Magno cuando este asediaba la ciudad pisida de Termeso ya sugiere una buena disposición al cambio (Arr., An. I 28.1), pero es la substitución del étnico epicórico por el griego $\Sigma \mathrm{E} \Lambda \Gamma \mathrm{E} \Omega \mathrm{N}$ en las series acuñadas a partir del 300 a. C. lo que no deja dudas acerca de sus aspiraciones identitarias ${ }^{57}$ : un nombre griego para una comunidad griega por derecho de descendencia ${ }^{58}$. En este desarrollo parece haber sido determinante el influjo de la llanura de Panfilia, en donde se daban unos condicionantes culturales e históricos aceptables ${ }^{59}$, y en especial

\footnotetext{
${ }_{55}$ Aunque no han sobrevivido, es probable, si se atiende al contenido de ISelge 6, que las estatuas que ocupaban los nichos fueran la del Dêmos de Selge y la del Dêmos de Esparta (Nollé y Schindler 1991, p. 76).

${ }^{56}$ La onomástica es muy reveladora a la hora de trazar una continuidad luvita en Pisidia, cf. Bryce 2003, p. 101.

${ }^{57}$ Brixhe 1976, p. 289; Zgusta 1984, p. 551; Heubeck 1985, p. 118; Nollé y Schindler 1991, p. 76.

${ }^{58}$ Ruby 2006 señala la descendencia y la etnonimia como los criteria definitorios de la identidad étnica.

${ }^{59}$ El propio nombre de la llanura sugería, por un lado, la idea de una población mixta y también ofrecía convenientemente, por otro, un vínculo con una de las tribus dorias, cf. Scheer 1993, p. 201 n. 297, p. 222.
} 
de Aspendo, ciudad con la que acuñaron moneda y a la que habrían tomado como modelo. Los selgeos aprendieron pronto el valor de los relatos fundacionales y, conscientes de los riesgos de quedarse rezagados, crearon un origen equiparable pero distinto al de sus vecinos. No hay que olvidar el que podría haber sido el foco originario de todo el proceso, la isla de Rodas, en donde además no es infrecuente la presencia de selgeos en época helenística (ISelge T 48-70) ${ }^{60}$. Su identidad griega recibirá un nuevo impulso durante la primera mitad del siglo III d. C. tras años de silencio, favorecida por las circunstancias históricas. Poco después la ciudad reviviría una leyenda de origen local, a semejanza de las polis de Etena, Isinda y Side, en la que el presunto héroe fundador, hijo del monte Tauro, habría sido recogido y protegido por la diosa Atenea, posiblemente una referencia a la cultura y a la civilización que trajeron los griegos (Nollé 1992, pp. 95-96) ${ }^{61}$. Selge parece haber tenido claro qué es lo que quería ser y cómo proyectarlo.

\section{BIBLIOGRAFÍA}

Aulock, H. von 1977: Münzen und Städte Pisidiens, I, Tubinga.

Bosworth, A. B. 1980: A historical commentary on Arrian's History of Alexander, I. Commentary on books I-III, Oxford.

Brixhe, C. 1976: Le dialecte grec de Pamphylie: documents et grammaire, París.

Brixhe, C. y Tekoğlu, R. 2000: «Corpus des inscriptions dialectales de Pamphylie. Supplément 5», Kadmos 39, pp. 1-56.

Bryce, T. R. 2003: «History», en Melchert, H. C. (ed.), The Luwians, Leiden-Boston, pp. 27-124.

Corsano, M. 1979: «Sparte et Tarente: le mythe de fondation d'une colonie», RHR 196, pp. 113-140.

Coulton, J. J. 2008: «Homer and the Solymians», en Kurtz, D. et al. (eds.), Essays in Classical archaeology for Eleni Hatzivassiliou 1977-2007, Oxford, pp. 17-25.

Curty, O. 1995: Les parentés légendaires entre cités grecques: catalogue raisonné des inscriptions contenant le terme ГYГГЕNEIA et analyse critique, Ginebra.

${ }^{60}$ Allí pudo haber coincidido alguno de ellos con Posidonio de Apamea, fuente usada por Estrabón, y haberle hecho saber no sólo la ascendencia lacedemonia sino también la relación con Calcante. Posidonio era el director de una escuela estoica en la isla, cf. de Hoz 2003, p. 15.

${ }^{61}$ El único testimonio es una moneda de época de Aureliano. Cf. en conjunto Nollé 1992, pp. 92-97, para la interpretación de estos mitos de autoctonía. 
Curty, O. 1999: «La parenté légendaire à l'époque hellénistique. Précisions méthodologiques», Kernos 12, pp. 167-194.

Curty, O. 2001: «Les parentés entre cités chez Polybe, Strabon, Plutarque et Pausanias», en Fromentin, V. y Gotteland, S. (eds.), Origines gentium [actes de 3 tables rondes, Bordeaux, décembre 1996-décembre 1997], Burdeos, pp. 49-56.

Curty, O. 2005: «Un usage fort controversé: la parenté dans la langage diplomatique de l'époque hellénistique», AncSoc 35, pp. 101-117.

de Hoz, M. P. 2003: Introducción, traducción y notas a Estrabón, Geografía, libros $X I-X I V$ (BCG 306), Madrid.

de Hoz, M. P. 2006: «Los solymoi: identidad, pervivencia y relación con licios, milyai y kabaleis», Geographia antiqua 14-15, pp. 77-88.

Derks, T. y Roymans, N. 2009: Ethnic constructs in antiquity: the role of power and tradition, Ámsterdam.

Dowden, K. 1999: «Reviewed work: Mythische Vorväter. Zur Bedeutung griechischer Heroenmythen im Selbstverständnis kleinasiatischer Städte by Tanja Susanne Scheer», Gnomon 71 1, pp. 26-30.

Elwyn, S. F. 1991: The use of kinship terminology in Hellenistic diplomatic documents: an epigraphical study, Ann Arbor.

Faraguna, M. 2003: «Alexander and the Greeks», en Roisman, J. (ed.), Brill's companion to Alexander the Great, Leiden-Boston, pp. 99-130.

Franke, P. R. y Nollé, M. K. 1997: Die Homonoia-Münzen und der thrakischen Randgebiete, I. Katalog, Saarbrücken.

French, D. H. 1994: «Isinda and Lagbe», en French, D. H. (ed.), Studies in the history and topography of Lycia and Pisidia. In memoriam A. S. Hall, Edimburgo, pp. 53-92.

Gonzales, M. 2005: «The oracle and cult of Ares in Asia Minor», GRBS 45, pp. 261-283.

Hall, A. S., Milner, N. P. y Coulton, J. J. 1996: «The mausoleum of Licinnia Flavilla and Flavianus Diogenes of Oinoanda: epigraphy and architecture», $A S$ 46, pp. 111-144.

Hall, J. 1997: Ethnic identity in Greek antiquity, Cambridge.

Hall, J. 2002: Hellenicity: between ethnicity and culture, Chicago.

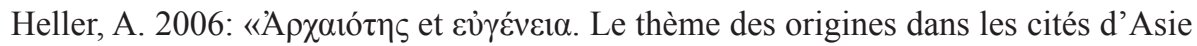
Mineure à l'époque impériale», en Zaidman, L. B. y Gherchanoc, F. (eds.),

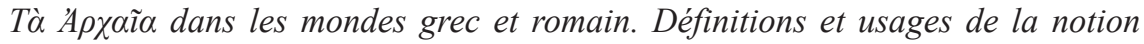
d'archaïsme, Ktèma 31, pp. 97-108.

Heller, A. 2009: «Généalogies locales et construction des identités collectives en Asie Mineure», en Bru, H., Kirbihler, F. y Lebreton, S. (eds.), L'Asie mineure dans l'antiquité: échanges, populations et territoires. Regards actuels sur une péninsule. Actes du colloque de Tours, 21-22 octobre 2005, Rennes, pp. 53-65. 
Heubeck, A. 1985: «Zu einigen kleinasiatischen Ortsnamen», Glotta 63, pp. 115-136. Jones, C. P. 1996: «The Panhellenion», Chiron 26, pp. 29-56.

Jones, C. P. 1999: Kinship diplomacy in the ancient world, Cambridge.

Jones, C. P. 2010: "Ancestry and identity in the Roman empire», en Whitmarsh, T. (ed.), Local knowledge and microidentities in the imperial Greek world, Cambridge, pp. 111-124.

Kearsley, R. A. 1994: «The Milyas and the Attalids: a decree of the city of Olbasa and a new royal letter of the second century BC», $A S$ 44, pp. 47-57.

Kosmetatou, E. 1997a: «The hero Solymos on the coinage of Termessos Major», SNR 76, pp. 41-63.

Kosmetatou, E. 1997b: «Pisidia and the Hellenistic kings from 323 to $133 \mathrm{BC}$ », $A S$ 28, pp. 5-37.

Lasserre, F. 1981: Strabon. Géographie. Tome IX (livre XII), París.

Lücke, S. 2000: Syngeneia. Epigraphisch-historische Studien zu einem Phänomen der antiken griechischen Diplomatie, Fráncfort.

Luraghi, N. 2008: The ancient Messenians. Constructions of ethnicity and memory, Cambridge.

Mac Sweeney, N. 2015: Foundation myths in ancient societies: dialogues and discourses, Filadelfia.

Malkin, I. 1994: Myth and territory in the Spartan Mediterranean, Cambridge.

Malkin, I. 2001: Ancient perceptions of Greek ethnicity, Cambridge.

Mitchell, S. 1991: «The hellenization of Pisidia», MedArch 4, pp. 119-145.

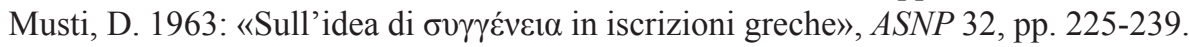

Nafissi, M. 1995: «Parte terza: la documentazione letteraria ed epigrafica», en Lippolis, E., Garraffo, S. y Nafissi, M. (eds.), Taranto. Culti greci in Occidente. Fonti scritte e documentazione archeologica, Tarento, pp. 155-334.

Nollé, J. 1992: «Zur Geschichte der Stadt Etenna in Pisidien», en Schwertheim, E. (ed.), Forschungen in Pisidien (Asia Minor Studien 6), Bonn, pp. 61-141.

Nollé, J. 2000: «Selge. Historisch-numismatisch Bemuhungen um die Kultur einer untergegangenen pisidischen Stadt», en Kluge, B. y Weisser, B. (eds.), XII. Internationaler Numismatischer Kongress, Berlin 1997: Akten - proceedings - actes, Berlín, pp. 706-714.

Nollé, J. 2007: Kleinasiatische Losorakel: Astragal- und Alphabetchresmologien der hochkaiserzeitlichen Orakelrenaissance, Múnich.

Nollé, J. 2009: «Die taurische Artemis in Tauros: Zeugnisse und Überlegungen zum Artemiskult von Termessos in Pisidien», en Tekin, O. (ed.), Ancient history, numismatics and epigraphy in the Mediterranean world: studies in memory of Clemens E. Bosch and Sabahat Atlan and in honour of Nezahat Baydur, Estambul, pp. 275-289.

Nollé, J. y Schindler, F. 1991: Die Inschriften von Selge (IGSK 37), Bonn. 
Paluchowski, A. 2008: «Les relations entre les villes de Crète centrale et celles de Pisidie et Phrygie sous le Haut-Empire: Gortyne et Selgé, Arkadès et Tibériopolis de Phrygie», DHA 34 (1), pp. 45-57.

Patterson, L. 2010: Kinship myth in ancient Greece, Austin.

Robert, L. 1977: «Documents d'Asie Mineure», BCH 101, pp. 43-132.

Robert, L. 1983: «Documents d'Asie Mineure», BCH 107, pp. 562-667.

Romeo, I. 2002: «The Panhellenion and ethnic identity in Hadrianic Greece», CPh 97 (1), pp. 21-40.

Ruby, P. 2006: «Peuples, fictions? Ethnicité, identité ethnique et sociétés anciennes», REA 108 1, pp. 25-60.

Saïd, S. 2001: «The discourse of identity in Greek rhetoric from Isocrates to Aristides», en Malkin, I. (ed.), Ancient perceptions of Greek ethnicity, Cambridge, pp. 275-298.

Sartre, M. 1994: El Oriente romano. Provincias y sociedades provinciales del Mediterráneo oriental, de Augusto a los Severos, Madrid.

Scheer, T. S. 1993: Mythische Vorväter. Zur Bedeutung griechischer Heroenmythen im Selbstverständnis kleinasiatischer Städte, Múnich.

Spawforth, A. J. y Walker, S. 1986: «The world of the Panhellenion II. Three Dorian cities», JRS 76, pp. 88-105.

Stroud, R. S. 1984: «An Argive decree from Nemea concerning Aspendos», Hesperia 53, pp. 193-216.

Strubbe, J. H. M. 1984: «Gründer kleinasiatischer Städte. Fiktion und Realität», AncSoc 15/17, pp. 253-304.

Takmer, B. y Gökalp, N. 2005: «Inscriptions from the sanctuary of Mí Oveүeıvos at Zindan Mağarası I», Gephyra 2, pp. 103-113.

Talloen, P. 2015: Cult in Pisidia: religious practice in southwestern Asia Minor from Alexander the Great to the rise of Christianity, Turnhout.

Thériault, G. 1996: Le culte d'homonoia dans les cités grecques, Quebec.

Vanhaverbeke, H. y Waelkens, M. 2005: “'If you can’t beat them, join them?' The hellenization of Pisidia», MedArch 18, pp. 49-65.

Waelkens, M. 2000: «Sagalassos and Pisidia during the Late Bronze Age», en Waelkens, M. y Loots, L. (eds.), Sagalassos V: report on the survey and excavation campaigns of 1996 and 1997 (Acta Archaeologica Lovaniensia Monographiae $11 A$ and $B)$, Lovaina, pp. 473-485.

Waelkens, M. 2004: «Ein Blick von der Ferne. Seleukiden und Attaliden in Pisidien», $\operatorname{MDAI}(I)$ 54, pp. 435-471.

Walbank, F. W. 1957: A historical commentary of Polybius, I. Commentary on books I-VI, Oxford.

Weiss, P. 1984: «Lebendiger Mythos. Gründerheroen und städtische Gründungstraditionen im griechisch-römischen Osten», WJA 10, pp. 179-208. 
Woodward, A. M. 1953: "Sparta and Asia Minor under the Roman Empire», en Mylonas, G. E. y Raymond, D. (eds.), Studies presented to D. M. Robinson, II, San Luis, pp. 868-883.

Woolf, G. 1994: «Becoming Roman, staying Greek: culture, identity and the civilizing process in the Roman east», PCPhS, pp. 116-143.

Zgusta, L. 1984: Kleinasiatische Ortsnamen, Heidelberg.

Fecha de recepción de la primera versión del artículo: 11/04/2014 Fecha de aceptación: 27/10/2014

Fecha de recepción de la versión definitiva: 02/12/2014 